\title{
Editor's Introduction to Contemporary Jewry v41(2)
}

\author{
Harriet Hartman ${ }^{1}$
}

Published online: 15 November 2021

(ᄋ) The Author(s), under exclusive licence to Springer Nature B.V. 2021

We open this issue of Contemporary Jewry with the two Marshall Sklare Memorial Award lectures of 2020. Professors Arnold (Arnie) Dashefsky and Chaim Waxman shared the monumental award celebrating 50 years of the founding of the Association for the Social Scientific Study of Jewry (ASSJ). Both were among the founders of ASSJ and both have exemplified the best traditions of Marshall Sklare, both individually and on occasion, in collaboration with each other. A word about the award, for those of you unfamiliar with it: since 1992, the Marshall Sklare Award has been given annually by the ASSJ to (a) senior scholar(s) whose scholarship has made a significant contribution to the social scientific study of Jewry, primarily through the publication of a body of research in books and articles or of published work related to public policy. A list of awardees can be found on ASSJ's webpage, http://www. contemporaryjewry.org/index.php/awards, spanning multiple fields of social science (sociology, demography, social psychology, anthropology, political science, communications, economics, history, communal service, religious studies and performance studies). Each year, the awardee(s) deliver(s) a significant lecture at the Association of Jewish Studies annual conference in December, and Contemporary Jewry is privileged to publish these addresses and any commentaries that are provided at the award session. Befitting the seniority in ASSJ of each of 2020's awardees, each chose to address the development of the field of the social scientific study of Jewry and/or the organization of ASSJ itself. Using the benefit of his penetrating wisdom based on far-reaching experience, Dashefsky takes us on a tour of the field, critically reflecting on the past, the present and the future in terms of scholarship and its context, ASSJ, the contrast between pessimistic and optimistic (his own) perspectives on these developments, and how to maximize the potential of the scholarly field and the organization (ASSJ) in the contemporary and future contexts. Also reflecting on 50 years of the sociological study of American Jewry, Waxman focuses on the statics vs. the dynamics of the field, providing us an historical perspective on his own development in the field and the development of Contemporary Jewry looking at persisting as well as shifting foci on topics such as American Jews' distanced and/or attached relationship to Israel, demography, and various attributes of Jewish identity

Harriet Hartman

Hartman@rowan.edu

1 Rowan University, 08028 Glassboro, Tzur Hadassah, New Jersey, Israel 
and practice. He concludes with a glance to the future of what the recent Pew 2020 survey of American Jews will reveal to us. (Stay tuned to future issues of Contemporary Jewry which will provide analyses of these new data.)

Please join me in congratulating these very deserving awardees as we look forward to their continuing contributions to the field.

The issue continues with the presentation of 11 rich articles spanning many fields in the social scientific study of Jewry. Six articles follow in the footsteps of Marshall Sklare's own studies, addressing various aspects of Jewish communities: from Emma Cieslik's qualitative study of a small Jewish college community in the Midwest, to David Marker's survey and critique of Jewish community studies' methodologies in the twenty-first century (note the intentional-and potentially controversial-plural of methodologies). Dikla Yogev discusses how the Haredi community negotiates communal and organizational boundaries, suggesting and demonstrating that faith-based organizations (like Zaka, which provides services in emergency disasters and more) can bridge between the ultra-Orthodox in Israel and the broader society, socializing members by offering opportunities to contribute to, integrate within, and be present in the public sphere. Perla Aizencang Kane explores boundaries between Jewish diasporas, Israeli diasporas (when Israelis are living outside of Israel-in this case in Mexico) and the problematics of constructing and maintaining identity and community. She uses the term "conviviality" to explore various levels of living together between various Jewish communities in Mexico, explored via rich mixed method research.

I placed John Cappucci's article on keeping kosher in Windsor-Essex, Canada, under this general section of "community" because the article discusses the infrastructure available in the community and how it is related to individual's/household's kosher habits. This is valuable qualitative information on how kashrut is actually understood and lived among contemporary Jews (how contemporary Jews "do kosher"). Maxim Samson's research on "white noise" addresses the delicate balance between security and community in contemporary synagogues, and provides a good segue into the next subtopic of the issue-antisemitism - for without the rise of antisemitic threats to the security of contemporary Jewry, the security issues would not have risen to the forefront of contemporary Jewish life in so many ways.

Three articles directly present research on antisemitism. The first is Graham Wright et al.'s presentation of research on Jewish American young adults' experiences and perceptions of antisemitism from 2017-2019, using a data set based on applicants to Birthright. The research provides needed contextualization of how perceptions of antisemitism are linked not only to experiences but also to the perceived climate for marginalized groups in the USA more generally. In his article, Daniel Kriegman critically analyzes Kevin MacDonald's work as a "racist misuse of evolutionary pseudoscience," giving us insight into a significantly influential thinker on contemporary antisemitism. Piotry Konieczny takes us to Poland and a focus on the use of language, tracing how the expression "Jewish paradise," once exclusively used xenophobically and antisemitically (originating in such a poem), has been reclaimed as neutral or even philosemitic in modern language use. These three articles span very different cultural contexts and foci in the context of contemporary antisemitism. 
We end the research articles with two perspectives on Jewish health. Yuval Arbel et al. look at the relationship between family size and the incidence of obesity, controlling for religiosity among Israeli Jews. Not only does this research show the importance of family and communal factors in the development of obesity, but it also contributes to our understanding of how religion, still a powerful social institution among contemporary Jews, can influence lifestyles with significant health consequences. The final research article analyzes the role of US synagogues in promoting the physical activity of youth - a meso-focus on the ramifications of organizational policies on yet another health-related attribute of contemporary Jewish lifestyles.

We conclude with two book reviews and a list of new books recently received for review. Jennifer Caplan reviews Jodi Eichner-Levine's Painted Pomegranates and Needlepoint Rabbis-yet another (and original!) perspective on creating Jewish communities and resilience. Marc Dollinger reviews Nancy Sinkoff's From Left to Right: Lucy S. Dawidowicz, The New York Intellectuals, and the Politics of Jewish History, which not only depicts Jewish life before and after World War II in both Europe and the USA, but also explores gender in an otherwise male-dominated sphere.

I trust you will find this issue particularly rich and I invite you to participate in a new series of online "Conversations" about its contents. Look for an announcement through the ASSJ-listserv and H-net. We look forward to hearing your thoughts, critiques, follow-up questions, and suggestions during these conversations and/or through emails to me or any member of the editorial board. Thanks for being our reader!

Publisher's Note Springer Nature remains neutral with regard to jurisdictional claims in published maps and institutional affiliations. 